\title{
Prescribing sodium oxybate for narcolepsy
}

\author{
Demanding that a patient's need is "exceptional" is irrational and should be abandoned
}

\author{
Adam Zeman chair of cognitive and behavioural neurology ${ }^{1}$, Zenobia Zaiwalla , consultant \\ neurophysiologist and non-respiratory sleep disorder lead clinician ${ }^{2}$
}

${ }^{1}$ University of Exeter Medical School, Exeter, Devon EX1 2LU, UK; ' ${ }^{J}$ John Radcliffe Hospital, Oxford OX3 9DU, UK

Narcolepsy affects around 4 in 10000 people, making it about one quarter as common as multiple sclerosis in the United Kingdom. ${ }^{1}$ Its cardinal features are excessive daytime sleepiness causing frequent, irresistible naps; cataplexy, leading to collapse, embarrassment, and sometimes injury; and marked disturbance of nocturnal sleep. It is usually due to a specific deficiency of the hypothalamic neurotransmitter hypocretin and most often starts in the teens, probably as the result of an autoimmune process. Narcolepsy is far more than an occasional dose of sleepiness: it is a lifelong, pervasive, and potentially disabling disorder with a similar effect on quality of life to treatment resistant epilepsy. ${ }^{2}$

While potentially disabling, it is also highly treatable. ${ }^{3} \mathrm{~A}$ combination of stimulants (typically modafinil or dexamfetamine or both) and antidepressants (to reduce cataplexy) improves symptoms appreciably in most patients. But treatment response may be partial; contraindications or side effects can prevent their use; and none of these drugs deals with the third cardinal symptom of narcolepsy, which is sometimes the most distressing - the fragmentation of nocturnal sleep.

Enter sodium oxybate (Xyrem) or $\gamma$-hydroxybutyrate (GHB), an agonist at $\mathrm{GABA}_{\mathrm{B}}(\gamma$-aminobutyric acid type $\mathrm{B})$ and $\mathrm{GHB}$ receptors. ${ }^{4}$ It has a chequered history. Following a period of use as a hypnotic and anaesthetic, GHB acquired a louche reputation as a date rape and recreational drug. More recently a series of trials have shown its efficacy in treating narcolepsy: given at night in two doses 3-4 hours apart, sodium oxybate consolidates nocturnal sleep, reduces excessive daytime sleepiness, and often abolishes cataplexy. Its potential to cause respiratory depression in overdose and substantial sedation at therapeutic doses, with attendant risks of falls in the night, enuresis, and new onset parasomnias, means that a careful approach to prescribing is needed, especially in patients with compromised respiration in sleep because of, for example, obstructive sleep apnoea. However, it is the only drug available for use in narcolepsy that simultaneously treats all three cardinal symptoms. Since it was licensed in 2006, we, in common with sleep specialists around the world, have found it a remarkably effective treatment. Despite the need for gradual titration and the nuisance of taking the drug twice nightly, many patients find sodium oxybate life transforming, often enabling them to return to work or to study after months or years of enforced absence.

Sodium oxybate is currently priced at around $£ 13000$ ( $€ 16764$; $\$ 18$ 929) a year at full dose, although many patients are optimally treated on lower doses. Prescribing policies around the UK are inconsistent. The Department of Health has agreed to underwrite its cost in selected vaccine related cases (a small narcolepsy epidemic followed the use of Pandemrix, a brand of H1N1 flu vaccine, in 2009-10). ${ }^{5}$ Some clinical commissioning groups have agreed sensible prescribing arrangements with local hospitals-for example in Cambridgeshire, ${ }^{6}$ London, and Merseyside. In most parts of the country, however, use of the drug requires the approval of an individual funding request, showing that a patient's need is "exceptional." 78

This process is tortuous, primarily because of the lack of clarity in the definition of exceptionality. Given the drug's cost, together with variations in the severity of narcolepsy and response to standard treatments, prescribing policies that restrict its use to more severely affected patients who respond poorly to other treatment seem sensible. But under the opaque operation of the exceptionality rule, a patient will be allowed sodium oxybate only if his or her response to the drug is judged likely to be exceptional compared with that of a patient with a similar degree of clinical need. This cannot be predicted from the available trial data. In our joint experience of around 30 applications, the increasingly rare agreements to fund the drug are emerging at random. Of 10 recent applications made by the authors in carefully selected patients, none has been successful. Reasons given for refusal have included the explanation that "the patient belongs to a cohort of similar patients." This logically necessary truth provides a convenient but empty justification for declining to fund valuable therapies.

Sodium oxybate is costly, potent, and should be prescribed with care. However, the individual funding request process is time wasting for doctors, frustrating for patients, and fundamentally irrational. It should be abandoned. We suggest that it should be replaced by agreements, like those mentioned above, to fund the drug, under the care of appropriate specialists, for patients 
who meet predetermined criteria, including more severe disease or failure of, contraindications to, or serious side effects from other treatments. We note that NHS England has recently issued a draft proposal relating to the use of sodium oxybate in postpubertal children ${ }^{9}$ along lines similar to these; we welcome this but can see no good reason for adopting different policies towards postpubertal children and adults. We hope that the recent decision to allow a judicial review of prescribing ${ }^{10}$ will lead to a more rational and equitable approach to the use of this expensive but valuable drug that is allowing many people with narcolepsy to maintain their personal and social relationships, achieve their academic potential, and remain in employment.

Competing interests: We have read and understood BMJ policy on declaration of interests and declare $A Z$ is on the medical advisory board of Narcolepsy UK, which is keen to see sodium oxybate become more widely available in the UK. He has given Narcolepsy UK no formal advice on this or any other topic for more than three years.

Provenance and peer review: Not commissioned; externally peer reviewed.

1 Dauvilliers Y, Arnulf I, Mignot E. Narcolepsy with cataplexy. Lancet 2007;369:499-511. doi:10.1016/S0140-6736(07)60237-2 pmid:17292770.
2 Broughton RJ, Guberman A, Roberts J. Comparison of the psychosocial effects of epilepsy and narcolepsy/cataplexy: a controlled study. Epilepsia 1984;25:423-33. doi:10.1111/j. 1528-1157.1984.tb03438.x pmid:6745214.

3 Billiard M, Bassetti C, Dauvilliers Y, et al. EFNS Task Force. EFNS guidelines on management of narcolepsy. Eur J Neurol 2006;13:1035-48. doi:10.1111/j.1468-1331 2006.01473.x pmid:16987156.

4 Boscolo-Berto R, Viel G, Montagnese S, Raduazzo DI, Ferrara SD, Dauvilliers Y Narcolepsy and effectiveness of gamma-hydroxybutyrate (GHB): a systematic review and meta-analysis of randomized controlled trials. Sleep Med Rev 2012;16:431-43. doi: 10.1016/j.smrv.2011.09.001 pmid:22055895.

5 British Sleep Society. Ex gratia provision of Xyrem to Pandemrix and narcolepsy personal injury claimants by the Department of Health. 2015. www.sleepsociety.org.uk/wp-content uploads/2015/05/Ex-Gratia-Xyrem-Scheme-Summary-13-March-2015.pdf.

6 Papworth Hospital NHS Foundation Trust. Shared care guideline: sodium oxybate: narcolepsy with cataplexy. 2014. www.cambsphn.nhs.uk/Libraries/Shared_Care_Guidance/ Sodium_Oxybate_for_Narcolepsy_with_cataplexy.sflb.ashx.

7 NHS England. Individual funding requests: a guide for patients and service users. 2015 www.england.nhs.uk/commissioning/wp-content/uploads/sites/12/2015/06/individl-fundreqts-info-pats.pdf

8 NHS Rationing. Relevant questions for patients and clinicians when a clinically effective treatment has been refused funding. 2012. nhsrationing.org/tag/exceptionality/.

9 NHS England. Clinical commissioning policy: sodium oxybate for symptom control of narcolepsy with cataplexy (children). 2016. www.engage.england.nhs.uk/consultation/ clinical-commissioning-wave8/user_uploads/e09x03-policy-prop.pdf.

10 Narcolepsy UK. Permission given for a judicial review into sodium oxybate funding refusal. 2015. www.narcolepsy.org.uk/blog/permission-given-judicial-review-sodium-oxybatefunding-refusal.

Published by the BMJ Publishing Group Limited. For permission to use (where not already granted under a licence) please go to http://group.bmj.com/group/rights-licensing/ permissions 